\title{
A Web-Based Electronic Learning of Local Nigerian Language; A Case of Ogba Language In Rivers State
}

\author{
Matthias, Daniel ${ }^{1}$, Nwaogwu, Onyekachi Best ${ }^{2}$, Igiri, Chima Godknows ${ }^{3}$ \\ ${ }^{1,2,3}$ Department of Computer Science, Rivers State University, Port Harcourt, Nigeria
}

\begin{abstract}
Language is a unique identity to every community in Nigeria; English has been a major communication medium in schools and high intuitions of learning. Over time this has posed as a threat on the indigenous languages in Nigeria were Ogba language is the primary focus, as this locally spoken languages will no longer exist based on the rapid growth of the English language in the local communities. There is this fear that Nigeria indigenous language is been traded off for English language as a major means of communication due to colonization.

This work is focused on the design and implementation of a webbased electronic learning system of Ogba language. The ObjectOriented Analysis and Design Methodology was adopted, the system is modelled with Unified Modelling Language and developed using HTML, CSS, JavaScript, PHP, SQL scripting language and MySQL as the database. This web-based application enables prospective learners to learn the language at their convenience in respective of location, in order to arrest the extinction that looms over the language.
\end{abstract}

Keywords: e-learning, translation system, Ogba language, English language.

\section{INTRODUCTION}

A $\mathrm{s}$ English language gains more prominence in both official and private circles in the country, ominous signs stab Yoruba, Igbo, Ogba and many other indigenous languages as less and less native speakers are not able to achieve fluency in their mother tongues, thus exposing the local languages to dangers of extinction in not too distant future. Language is a cultural identity; is one of the popular ways outside of dressing or food that makes it possible to identify people of a particular tribe. As much as the language of our colonial masters makes for better exchange of information and ideas, it has had an adverse effect on our local languages making some of them endangered.

Although, there are many definitions of language e-learning and translation system, google translator is one of the biggest language learning and translating system, this system covers only but four spoken Nigerian language (Pidgin, Yoruba, Hausa, and Igbo) apart from several international languages, it's important to note that this system is not tailored to the local and smaller communities like Ogba language and its lack of audio pronunciations in the afore mentioned Nigeria languages makes it difficult for a user to learn the true pronunciations of words, given that Ogba language is a tonal language, and will become difficult to learn without its pronunciations
There has been a problem in the already existing system as the issues of mother tongue language is not addressed, as provision for other tribes, like Ogba language was not put into consideration. Even the available Nigeria language that is implemented on this system suffer from translation errors and the lack of audio pronunciation makes it difficult for a user to learn the true pronunciations of words as the pronunciations of these translated words varies base on the intonations.

For example: gha (a kind of vegetable leaf) and ghã (town).

The system will provide opportunities for the younger generations who will be mostly affected, to learn the language and speak the language.

\section{RELATED WORKS}

In early 1990s sites on the Internet, such as AltaVista's Babel Fish (using Systran technology) and Google Language Tools (also initially using Systran technology exclusively). Odetunji (2014) worked on Text to Speech Synproject at Obafemi Awolowo University, Ile Ife, Nigeria, and Dr. Wanjiku Ng'ang'a working on Machine Translation and Dr. Peter Wagacha working on Machine Learning, both at the University of Nairobi, Kenya.

Yoruba 101 is developed by Genii Games last updated (January 29, 2018) is an android mobile application developed only for the yoruba's, Igbo Language E-Learning System: paper as presented by Oyelami, Olufemi Moses presents a standalone Igbo language learning system.

However, the available lingual system did not support Ogba language.

A number of available texts also exist in Ogba.

Akinwotu (2018) worked on Language and Style in Political Inaugurals: A Study of Inaugural Speeches of Governor Olusegun Mimiko of Ondo State, Nigeria. adopts a combination of stylistics and Michael Halliday's Systemic Functional Grammar as approaches to examine the patterns of language use in the inaugural speeches of Governor Olusegun Mimiko of Ondo State with the view to uncovering the specific stylistic choices that characterize the speeches and their pragmatic import.

Motsaathebe (2019) presents insights derived from an exploratory study concerning the viability of the newspapers that use indigenous African languages in South Africa in this era of new media and an increasingly English-speaking world. 
Among these researchers non has cover community spoken languages like the Ogba language as this study will provide solutions to the learning and speaking of the Ogba language, using a web-based platform thereby providing opportunities for its users to learn the language in respective of location and time, as learning can happen on the system simultaneously.

According to UNESCO (2012), "A language is endangered when its speakers cease to use it, use it in fewer and fewer domains, use fewer of its registers and speaking styles, and/or stop passing it on to the next generation." languages may become endangered and later go into extinction when its speakers die off or abandon their language and switch to another.

\section{Language Endangerment}

Folorunso (2016), "Many Nigerian indigenous languages are faced with a lot of challenges and their continuous existence is being threatened, it is a known fact that in most of the educated elites' homes, children are not encouraged to speak their mother tongues but English." Hence, a language lives, it can also die, based on numerous factors such as the attitude of the language owners. Positive attitude enhances language growth and development, negative attitude leads to its endangerment and subsequent its death.

Every language is special in its unique way and endows this uniqueness on the social landscape where it flourishes. When the speakers of a language abandon their language in favour of a more populous, prestigious, or economically viable one, they give up their birthright, since their language embodies their distinctive, self-defining civilisation and symbolises their exclusive contributions to human knowledge and development. When a language dies, an irreplaceable intellectual and social wealth of the people also dies, and the larger society's pool of educational, social and cultural values is diminished. The death of any language is a tragedy, Usman (2014).

\section{Vowels in Ogba Language}

Ogba exhibits vowel system, which comprises nine vowels [a e i o u e i i o ụ], four of which are without subdots [ e i o u] and the remaining four [ e i i o u ] have subdots, while one is neutral [a]. There are no nasal vowels but all nine vowels can be nasalized in proximity to a nasal consonant. Table 1 indicates that Ogba has a symmetrical set of front [ e i e i i] and back [ o u o u $]$ vowels and a low central vowel [a]. The different phonemes are exemplified below:

Table 1: Ogba vowel inventory

Without subdots with subdots

\begin{tabular}{|c|c|c|c|c|}
\hline & \multicolumn{2}{|c|}{ FRONT BACK } & \multicolumn{2}{|c|}{ FRONT BACK } \\
\hline CLOSE & $\mathrm{i}$ & $\mathrm{u}$ & $\mathrm{i}$ & ụ \\
\hline MID & $\mathrm{e}$ & o & ẹ & ọ \\
\hline OPEN & & & & \\
\hline
\end{tabular}

\begin{tabular}{|c|c|c|c|c|}
\hline \multicolumn{2}{|c|}{ Orthographic } & Phonetic & Ogba & English \\
\hline $\mathrm{i}$ & [i ] & isi & [isi ] & Head \\
\hline$\stackrel{1}{1}$ & [I] & ịba & [ Iba ] & fever \\
\hline $\mathrm{e}$ & [e ] & epre & [ epre ] & plate \\
\hline ẹ & {$[\varepsilon]$} & ẹba & [ $\mathrm{cba}]$ & feather \\
\hline a & [a ] & abọ & [abo ] & long basket \\
\hline o & [o ] & olŭ & [ olŭ ] & Neck \\
\hline ọ & [o ] & ọbọ & [ obo ] & Orange \\
\hline $\mathrm{u}$ & {$[\mathrm{u}]$} & ube & [ube ] & Pear \\
\hline ụ & [u ] & ababa & [ababa] & sand fly \\
\hline
\end{tabular}

\section{Learning Strategy}

This focuses on learning strategy, matching learning experiences and content. Presentation and distribution methods offer a wide array of options and require extensive technical infrastructure. The most widely used presentation methods are Web-Based Training (WBT), Computer-Based Training (CBT), and teleconferencing.

Matching content to delivery is critical because different presentation and distribution methods best support various learning experiences. Regardless of presentation and distribution method, e-learning effectiveness depends on its deployment strategy, ease of use, and content quality and relevance (Burns et al, 1991)

\section{SYSTEM ARCHTECTURE}

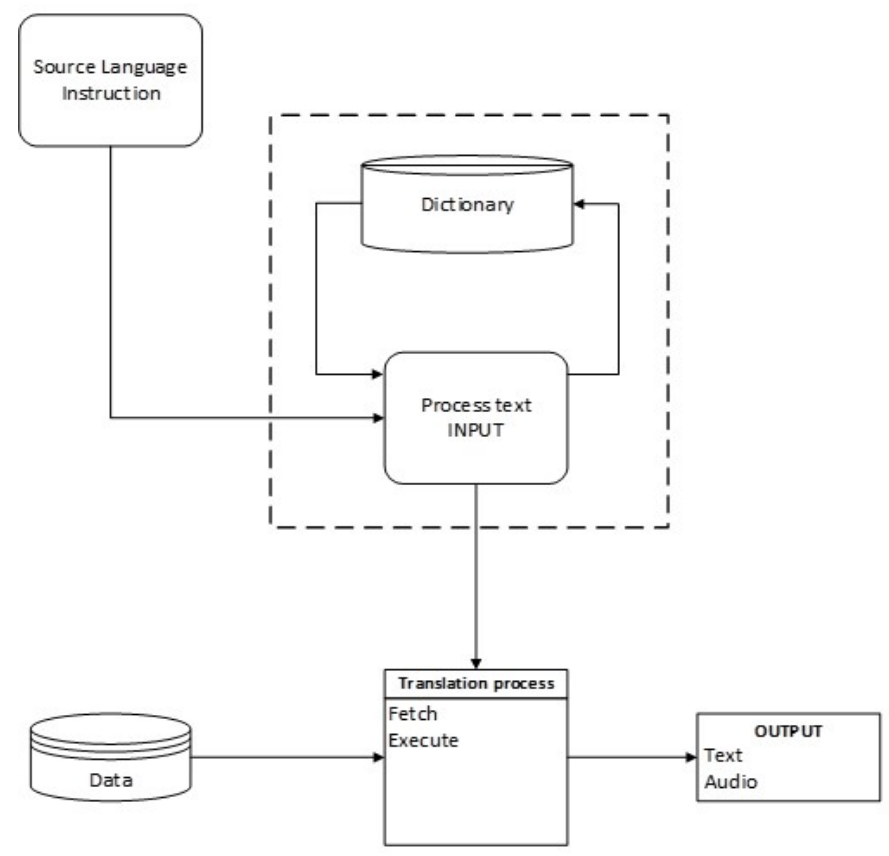

Figure 1: Architectural Design

\section{METHODOLOGY}

The Object-Oriented System Analysis and Design Methodology (OOSADM) process is adopted for the research 
work, as each section of is broken down into different modules.

\section{Analysis of the system}

The system is developed with a list of selected words consisting of the English language along with its corresponding translated version of the target language (Ogba language). The system will carry out the following task;

i. Check if the word to be translated exists on the system database.

ii. If the word to be translated exists, then display the translated version of the word and its audio pronunciation.

iii. But if the word to be translated is not found on the system database then store the searched word on the system database.

The meanings of the stored words are provided by other users of the system and approved by an authorized lingual user of the system. Some of these exiting systems lacked some of these features most especial the audio pronunciations of the translated word.

\section{Input Output description}

The data textual input is collected from a second level user which is an anonymous user of the system, and textual and audio input is collected from first level user of the system (lingual user) and the result is at the end of each query is either textual, audio pronunciation or both.

The primary input sources language is English which is processed and check against the dictionary before translation is fetched and the output is displayed.

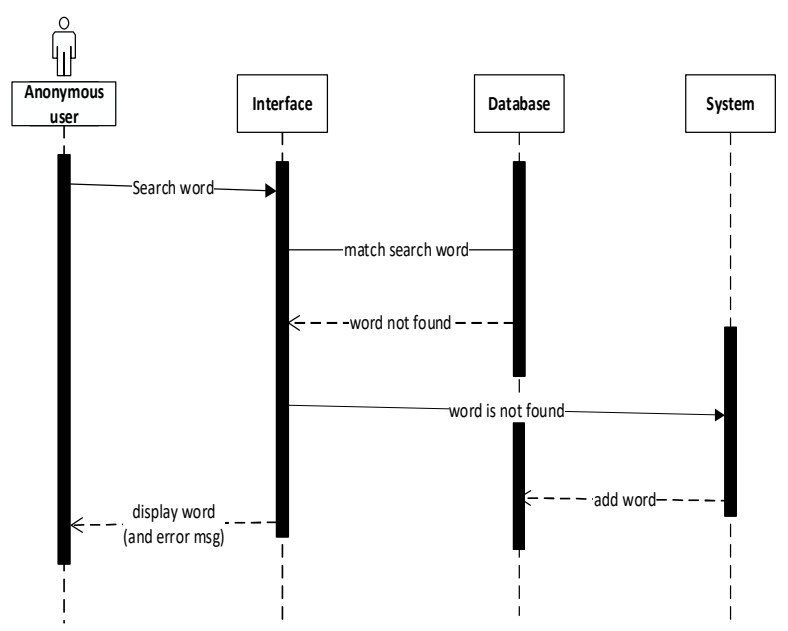

Figure 2: Sequence diagram (User translations for word not found)

The sequence of steps as illustrated above is only applicable when a word to be translated is not found on the dictionary, and is then stored on the database (new-word-dictionary) and the user is notified about the unavailability of the searched word.

\section{System Overview}

The system accepts a textual input form the anonymous user, this input is check against the dictionary, if it matches any of the word that is pre-defined in the dictionary then the system looks for the marching translations for the word and the relevant audio pronunciation data is fetched and is sent back to the user that issues the query to the translation.

Alternatively, the textual input when checked against the dictionary and is not found, then the inputted word is stored on the database (new-dictionary) and a notification is sent to the user that the translation of the word is not available at the moment.

The system in a situation where there are word(s) that is stored on the database (new-dictionary), the system automatically displays this word(s) to the users to provide possible suggestions to the untranslated word(s). When this is done by an anonymous user the system sends the data to the modulations section where the translated data will be awaiting approval from the linguist users before been added to the dictionary and the translation.

The linguist user is the one that knows the dialect and is fluent in speaking and translating the language. This user checks the modulated words to verify, modify and approve the suggested translations, also ensuring that the right pronunciation is been provided for the translated word, this user has the privilege to add new words and their translations into the dictionary.

For this user to carry out these features of the system he/she must be register and must be logged in.

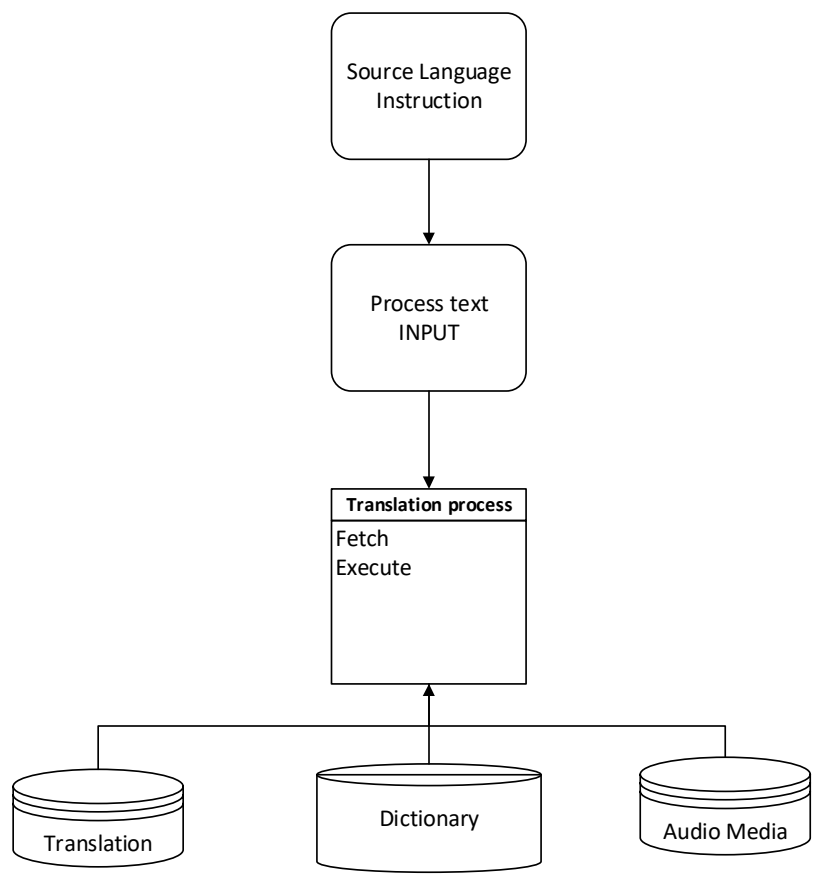

Figure 3: hieratical model of the system 


\section{RESULTS/DISCUSSION}

\section{System Implementation}

The implementations and testing, on how each of the components is to functions with each other illustrating how the objective of the proposed system is achieved.

The proposed system is said to have fulfilled the objective of storing words that are not on the language dictionary, requesting for possible suggestions from users about new words, and provide the audio pronunciation for each searched word as Ogba language pronunciation for easier learning.

\section{User Module}

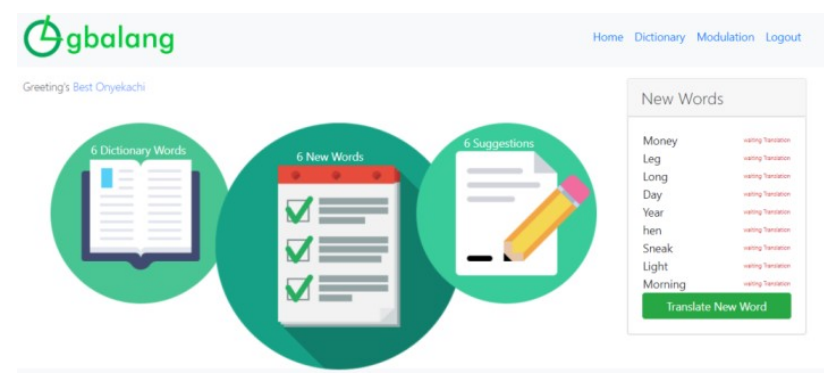

Figure 4: System interface

This module gives the user access to input a word in the text area below and by clicking on the translate, the translated version of the inputted word is fetch and the audio button is activated, when the user clicks on it the word is been pronounced.

\section{Linguist Module}

With this module the linguist has access to login to the system in other to carry out further operations by providing username and password.

\section{User Suggestion}

The suggestion section if a user knows the meaning of any word and want to suggest the meaning

of that word, the user just clicks on the green button written "suggest" and type the meaning of the word in the input filed that will be provided.

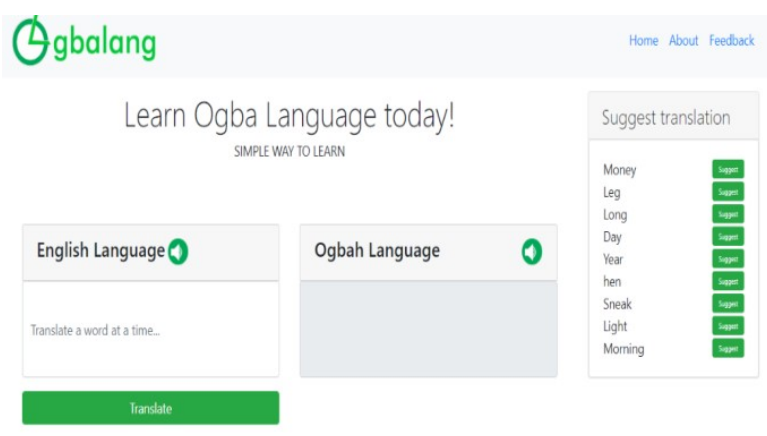

Figure 5: Linguistic Dashboard

\section{Linguist Menu/Dashboard}

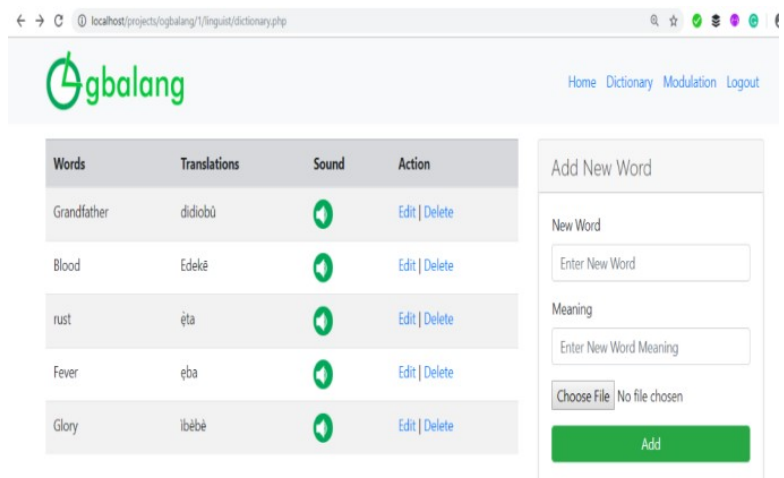

Figure 6: Lingual Interface for adding new word to dictionary

Upon the verification of the username and password the Linguist is granted access to navigate through the system to perform a giving operation at a time.

\section{Programing Languages}

The system is implemented using HTML, CSS, JavaScript, PHP and MYSQL programming language. This language has the advantage of easy development, flexibility and has ability of providing the developer/programmer with possible hints and it produces a graphical user interface.

\section{Software Testing}

After design and development, the system was tested when queried for a given word the desired textual translation output was displayed on the monitor alongside with the audio pronunciation of the translated word in the Ogba dialect. When this user clicks on the audio button that is activate then the translated world is been pronounce. But for those words that were not found on the system are stored on the database of the system and displayed on suggestion section of the system.

This has proven that the new system works perfectly and effective as designed and its requirements has been met.

As its important to test to see how effective and efficient the system is, the following testing was conducted; unit testing, component testing, integration testing and software testing. So, testing began from each unit before conducting the overall system testing and 75 percent of all errors were uncovered and 20 percent where discovered during all program component testing.

This testing ensures that internal operations are performed according to specifications and all internal components have been adequately exercised.

\section{CONCLUSION}

This research work focuses on the use of computer system with reference to the learning of Ogba language, it covers the manual system of operations as regards the problems 
identified, stating the aims of the new system, stating the various specifications and the implementation of the system.

The research was developed using HTML, CSS, JavaScript, Bootstrap, PHP and MYSQL the system was tested and improved upon which yielded an e-learning system for the learning of local Nigeria language, case study of Ogba language.

This research work cannot be said to be perfect, but however, its benefits cannot be overemphasized. It has led to the improvement in the learning of the Ogba language, translation and improved storage of data.

The Ogba language is a complex language with many dialects making it difficult to identify the central Ogba from other dialects.

E-learning systems have a large advantage over traditional learning environment as it eliminates the tension and distance barrier of learning Ogba language. The web-based e-learning system developed for the learning of Ogba language is an alternative to solve the problem of lack of continuity of the language, and gives room to both the urban and rural area dwells to learn the meaning of words in the language alongside its pronounced.

This work is a step in the right direction of arresting the extinction that looms over Ogba language as an e-learning system has been presented.

The present study is significant as it might lead to the attainment of the following:

a. The study becomes a reference material for linguists, language teachers and students as well as those interested in sociolinguistic literature.

b. The study has some practical outcome, for instance, to motivate the Ogba community in encouraging them, to re-empower their language or empower it further.

c. The study might stimulate the interest of other Nigerian scholars especially those of Ogba to undertake further research on Ogba language and/or other languages.

d. It is also hoped that the study serves as enlightenment for government and might therefore trigger policies on indigenous languages in general and those of Rivers State and Ogba in particular.

\section{FURTHER WORKS}

The current version of this research work performs translations of only one word at a time which is part of a complete sentence and its pronunciation. In further research in this related work, it is recommended that the following futures should be added to better the system, sentence translation with pronunciation, and possibly the use of machine learning techniques in future research.

\section{REFERENCE}

[1] Ahiamadu, A. (2000). Reading and Writing Ogba. Printed by Outreach Publications, P.M.B. 6221, Port Harcourt.

[2] Akinwotu S. A. (2018). Language and Style in Political Inaugurals: A Study of Inaugural Speeches of Governor Olusegun Mimiko of Ondo State, Nigeria. British Journal of English Linguistics, 6(5), 1-15.

[3] Clark, J. D. (1971). Reading and Writing Ogba Rivers Readers Publication, Port Harcourt.

[4] Balogun, T. A. (2013). An Endangered Nigerian Indigenous Language: The Case of Yorùbá Language. African Nebula, (6).

[5] Bellos, D. (2011). Is That a Fish in your Ear? Translation and the Meaning of Everything. London: Penguin Books.

[6] Bowker, L., and Pearson, J. (2002). Working with Specialized Language: A Practical Guide to Using Corpora. London and New York: Routeledge

[7] Braimoh, D. (2012), Lifelong Learning and the Imperatives of New Technologies. 7th DisCo Conference on New Media and E.

[8] DotCasda (2013). Learn Basic Yoruba, Resource Available at: https://play.google.com/store/apps/details?id=com.gratelabs.learn yoruba. Retrieved: 20th March 2019.

[9] Ellah J. (1995). The Ogba people of the Niger Delta. Unpublished Long Essay.

[10] Eke, L., and Ugorji, J. (1999). Studies in Translation. Enugu: John Jacob's Classic Publishers Ltd. Emenanjo .

[11] Genii G. (2014). Igbo 101, last updated (January 29, 2018). Available:

https://play.google.com/store/apps/details?id=air.igbo101and\&sh owAllReviews=true Retrieved: 20th March 2019.

[12] Lopez, C. (2007). "fully automatic high-quality translation of unrestricted text"

[13] Khalifa, M. and Lam, R. Web-based learning (2002): Effects on learning process and outcome. IEEE Tran. on Education 45 (4):350-356.

[14] Kim, B., Park, H. and Baek, Y (2009). Not just fun, but serious strategies: Using meta-cognitive strategies in game-based learning. Journal Computers \& Education 52: 800-810.

[15] Manfredi, V. (1989). Igboid. The Niger-Congo languages, ed. by John Bendor Samuel, 337-58. Lanham, Maryland: University Press of America.

[16] Motsaathebe, G. (2019). Indigenous language media and the onslaught of multimedia platforms and English language hegemony in South Africa: Industry roleplayers' perspectives, presented at a Conference on English and the Dynamics of Global Access, University of Botswana, Gaborone, June 19-21, 2019.

[17] Ngozi P. I. and Olivia E. (2015). Translating technical texts: The Igbo language example, National Institute for Nigerian Languages, Aba, Nigeria.

[18] Oburu O. and Chijioke E. (2009). Ogba Orthography. Unpublish Manuscript.

[19] Odetunji O. (2014). A research on Text to Speech Synproject: Obafemi Awolowo University, Ile Ife, Nigeria.

[20] Ogba Language Committee (1994). A dictionary of Ogbà, an Igboid Language of Southern Nigeria. Published by: Roger Blench Kay Williamson Educational Foundation, 8 Guest Road Cambridge CB1 $2 A L$ United Kingdom.

[21] Ohia E. and Onyedibia A. (2004). Ekvvo Olu Ogba Nka Mbu. Rivers Readers Publication, Port Harcourt.

[22] Otuwarikpo, F. E. 1994. History of the Origin of Ogba, Unpublished Thesis.

[23] Oyelami, O. M. (2008). "Igbo Language E-Learning System" Department of Computer and Information Sciences Covenant University, OTA, Nigeria Published by: Turkish Online Journal of Distance Education-TOJDE October 2008 ISSN 1302-6488 Volume: 9 Number: 4 Article 2.

[24] Ozomekuri N. (2011). Orthographies of Nigeria Languages manual ixPublished by: Nigerian Educational Research \& Development Council.

[25] Peter W. (2009) Machine Learning. A Research project, University of Nairobi, Kenya. 
[26] Selim, H. M. (2007). Critical success factors for e-learning acceptance: Confirmatory factor models. Journal Computers \& Education 49:396-413.

[27] Sun, P. and Yeh, D, (2008). What drives a successful e-learning? an empirical investigation of the critical factors influencing learner satisfaction. Journal Computers \& Education journal 50: 11831202.

[28] Roach, P. (1992). Phonetics and Phonology of English. Our native tongues are going extinct, https://www.pulse.ng/lifestyle/food- travel/nigerian-languages-our-native-tongues-are-goingextinct/kp8072g. Retrieved: 03rd March 2019.

[29] Roux S. (2008). A report on HLT (Human Language Technology). development in Sub-Saharan Africa

[30] Venter, I. M. and Blignaut, R. J, (1996). Approach to computer literacy in a third world education setting. Journal Computers Education27 (1): 23-29.

[31] Warren W. (July, 1949). A proposal for machine translation using computers $A$ researcher at the Rockefeller Foundation. 